\title{
Comunidades de fungos micorrízicos arbusculares associados ao amendoim forrageiro em pastagens consorciadas no Estado do Acre, Brasil
}

\author{
Elias Melo de MIRANDA ${ }^{2}$ Eliane Maria Ribeiro da SILVA², Orivaldo José SAGIN JÚNIOR ${ }^{3}$
}

\begin{abstract}
RESUMO
O objetivo deste trabalho foi identificar e estimar a diversidade de comunidades de fungos micorrízicos arbusculares (FMAs) autóctones associados ao amendoim forrageiro (Arachis pintoi), em monocultivo e consorciado com outras forrageiras. A amostragem foi realizada em sete áreas, em Rio Branco, AC, sendo coletadas quatro amostras de solo em cada área, na profundidade de $0-10 \mathrm{~cm}$, nas estaçóes seca (junho de 2004) e chuvosa (janeiro de 2005). As áreas cultivadas com $A$. pintoi foram: monocultivo, consórcio com pastagens de gramíneas e outras leguminosas e como cobertura do solo em cafeeiro, além de capoeira e mata adjacentes como testemunhas. Foi verificada a ocorrência de 21 espécies de FMAs nas duas estaçôes, sendo 18 espécies no período seco e 16 no chuvoso. As espécies foram distribuídas em cinco gêneros: Acaulospora, Entrophospora, Gigaspora, Glomus e Scutellospora. A densidade de esporos foi maior no consórcio A. pintoi x Brachiaria brizantha x Pueraria phaseoloides e a menor nas áreas de $A$. pintoi x cafeeiro, capoeira e mata. As colonizaçôes radiculares foram maiores na estação chuvosa (15 a 63\%) do que na estação seca (5 a 37\%). Os índices de diversidade no monocultivo foram semelhantes aos das demais áreas avaliadas, indicando que o amendoim serve como hospedeiro de diferentes espécies de FMAs e que o seu cultivo pode aumentar a presença desses organismos nos sistemas produtivos, melhorando a qualidade biológica do solo.
\end{abstract}

PALVRAS-CHAVE: Arachis pintoi, diversidade de micorrizas, Amazônia.

\section{Communities of arbuscular mycorrhizal fungi associated with peanut forage in mixed pastures in the state of Acre, Brazil}

\begin{abstract}
The purpose of this study was to identify the autochthonous communities of arbuscular mycorrhizal fungi (AMF) associated with Arachis pintoi and estimate its diversity. Samples of soil were collected in a Field at Rio Branco, AC. The sampling was carried out in seven areas, being collected four samples from soil in each area, in a depth of $0-10 \mathrm{~cm}$, in dry season (June 2004) and rainy season (January 2005). The areas cultivated with $A$. pintoi were: monoculture, grass pasture and others legumes intercropped, coffee plant under cover of $A$. pintoi, besides brush and forest adjacent like a control. It was verified the occurrence of 21 species of AMF in the two seasons, 18 species in the dry period and 16 in the rainy. The species were distributed in five genres: Acaulospora, Entrophospora, Gigaspora, Glomus and Scutellospora. The densities of spores were higher in A. pintoi x Brachiaria brizantha x Pueraria phaseoloides intercropped and lowest in the areas of A. pintoi x coffee plants, brush and forest. Mycorrhizal colonization was higher in the rainy season (15 to 63\%) than in the dry season (5 to 37\%). The diversity indices in monoculture were similar to those of other areas evaluated, indicating that the $A$. pintoi serves as host of AMF of different species and that its cultivation may increase the presence of these organisms in production systems, improving the biological soil quality.
\end{abstract}

KEYWORDS: Arachis pintoi, diversity of mycorrhiza, Amazonia.

\footnotetext{
1 Empresa Brasileira de Pesquisa Agropecuária, Embrapa - Acre, e-mail: elias@cpafac.embrapa.br

2 Empresa Brasileira de Pesquisa Agropecuária, Embrapa, e-mail: eliane@cnpab.embrapa.br

${ }^{3}$ Empresa Brasileira de Pesquisa Agropecuária, Embrapa, e-mail: saggin@cnpab.embrapa.br
} 


\section{INTRODUÇÃO}

$\mathrm{Na}$ regiấo Amazônica, a substituiçáo da floresta nativa por pastagem tem levado ao empobrecimento e degradaçáo dos solos, devido a vários fatores, entre eles a falta de aptidão dos solos para a atividade pecuária e o manejo inadequado da pastagem. A remoção da cobertura florestal torna o ecossistema frágil, sujeito ao processo de degradaçáo. Portanto, o equilíbrio entre a vegetaçáo e o componente biológico do solo é essencial para a manutenção da fertilidade, possibilitando a ciclagem e a solubilização de minerais.

As pastagens na região amazônica, geralmente, têm um curto período produtivo, devido a não reposição, em quantidade adequada, de nutrientes fundamentais como o $\mathrm{N}$ e o P, sendo o aspecto nutricional uma das causas de sua degradação. Atualmente, assume-se que, especialmente em pastagens tropicais, a palha depositada sobre o solo e as raízes são as principais responsáveis pela incorporação de $\mathrm{N}$ nos sistemas (Cadish et al., 1994; Boddey et al., 1995). Em monocultivos de gramíneas, as deposiçóes constantes da palhada, de alta relação $\mathrm{C} / \mathrm{N}$, por longos períodos, levam à imobilização do $\mathrm{N}$ solúvel na biomassa microbiana, tornando-o indisponível às plantas e animais. Em conseqüência, a carência de $\mathrm{N}$ solúvel limita a decomposição da serapilheira e a mineralizaçáo da matéria orgânica (Schunke, 1998).

A solução para aumentar a longevidade produtiva de uma pastagem nas regióes tropicais, sem o uso de fertilizantes químicos, passa necessariamente pelo plantio de leguminosas forrageiras em consórcio com gramíneas. As leguminosas suprem a carência de $\mathrm{N}$ do sistema, por meio da fixaçáo biológica, possibilitando a manutenção da atividade biológica do solo e conseqüentemente da ciclagem de nutrientes (Cadisch et al., 1994; Cantarutti,1996). Este processo pode ser bastante acelerado quando a leguminosa é inoculada com uma estirpe de rizóbio eficiente (Thomas, 1992).

Outros organismos importantes na manutenção da fertilidade do solo são os fungos micorrízicos arbusculares (FMAs). Em solos de média a baixa fertilidade, como os da Amazônia, estes organismos contribuem para aumentar a eficiência no transporte e absorção de nutrientes, principalmente daqueles de baixa mobilidade no solo, como P, Zn e Cu (Oliveira et al., 2003; Oliveira et al., 1999; Smith et al., 1994), tornando-os mais biodisponíveis. As micorrizas são consideradas um importante componente na recuperação e restabelecimento da vegetaçấo em ecossistemas frágeis ou degradados, bem como na manutenção da biodiversidade de plantas e no funcionamento do ecossistema (Dandan $\&$ Zhiwei, 2007).

$\mathrm{O}$ alto custo de insumos agrícolas na região amazônica, especialmente de fertilizantes e corretivos, junto à crescente demanda por tecnologias menos agressivas ao meio ambiente, torna o manejo ecológico dos organismos do solo uma prática promissora, podendo contribuir para aumentar a sustentabilidade dos sistemas agrossilvipastoris na Amazônia. Portanto, o conhecimento da diversidade e dinâmica dos organismos do solo é importante para o desenvolvimento de sistemas de manejo mais eficientes.

Este estudo parte da hipótese de que as comunidades de FMAs são influenciadas pelo grau de complexidade da cobertura vegetal e que o amendoim forrageiro (Arachis pintoi Krap. \& Greg.) contribui para aumentar a presença desses fungos no solo. O objetivo deste trabalho foi identificar as comunidades de FMAs autóctones associadas ao amendoim forrageiro e estimar a diversidade desses microrganismos em áreas com diferentes coberturas vegetais no Estado do Acre, nas estaçóes seca e chuvosa, com ênfase em pastagens consorciadas.

\section{MATERIAL E MÉTODOS}

As amostras de solo foram coletadas na Estação Experimental da Embrapa Acre, situada no $\mathrm{km} 14$ da rodovia BR 364, no Município de Rio Branco, AC, a 958'22” S e 6748’40” W, e altitude de $160 \mathrm{~m}$, sendo levadas para a Embrapa Agrobiologia, em Seropédica, RJ, onde foram feitas as análises de laboratório e os ensaios em casa-de-vegetação.

$\mathrm{O}$ ecossistema original da área era floresta tropical úmida e vem sendo cultivada desde meados da década de 70 , principalmente com gramíneas forrageiras e o Arachis Pintoi foi introduzido a partir na década de 90 . O clima da região é tropical úmido tipo Awi (Köppen), com precipitação anual variando entre 1800 e $2000 \mathrm{~mm}$, temperatura média anual de $24,7^{\circ} \mathrm{C}$ e estação seca e úmida bem definida (Mesquita $\&$ Paiva, 1995; Mesquita, 1996; Acre, 2000).

O solo da área amostrada foi classificado como Argissolo Vermelho-Amarelo, apresentando as seguintes características físicas, em g. $\mathrm{kg}^{-1}$ : argila 236, silte 389 e areia 375 . As características químicas do solo em cada área estudada são mostradas na Tabela 1.

Tabela 1 - Características químicas do solo na profundidade de 0-10 cm nas áreas de coleta.

\begin{tabular}{lcccccccccc}
\hline $\begin{array}{l}\text { Cobertura } \\
\text { vegetal }\end{array}$ & $\begin{array}{c}\mathrm{pH} \mathrm{em} \mathrm{H} \mathrm{H}_{2} \mathrm{O} \\
(2: 1)\end{array}$ & $\begin{array}{c}\mathrm{Al}^{3+} \\
\mathrm{Cmol}_{\mathrm{c}} \cdot \mathrm{Cm}^{-3}\end{array}$ & $\mathrm{Ca}^{2+}$ & $\mathrm{Mg}^{2+}$ & $\mathrm{P}$ & $\mathrm{K}$ & $\mathrm{C} \cdot \mathrm{dm}^{-3}$ & & \multicolumn{3}{c}{$\mathrm{M} \cdot \mathrm{g} \cdot \mathrm{kg}^{-1}$} & $\mathrm{~N}$ \\
\hline ApMono & 5,1 & 0,6 & 1,3 & 0,6 & 2,3 & 46,4 & 6,2 & 10,6 & 1,3 \\
Ap x Pm & 5,4 & 0,1 & 3,8 & 0,4 & 3,4 & 107,5 & 8,9 & 15,3 & 1,4 \\
Ap x Bb & 5,3 & 0,4 & 4,3 & 0,6 & 4,3 & 90,4 & 13,8 & 23,8 & 1,7 \\
Ap x Bh & 5,5 & 0,1 & 2,7 & 0,4 & 1,0 & 98,9 & 10,4 & 17,9 & 1,8 \\
Ap xc afé & 5,1 & 0,7 & 1,8 & 0,4 & 3,0 & 92,9 & 6,3 & 10,9 & 1,2 \\
Capoeira & 6,8 & 0,0 & 4,1 & 0,5 & 3,5 & 65,9 & 12,3 & 21,2 & 1,5 \\
Mata & 5,1 & 1,3 & 5,6 & 0,9 & 1,7 & 82,4 & 11,6 & 19,9 & 2,0 \\
\hline
\end{tabular}


ApMono $=A$. pinto $i$ em monocultivo; $\mathrm{Ap} \times \mathrm{Pm}=A$. pinto $i$ consorciado com Panicum maximum; $\mathrm{Ap} \times \mathrm{Bb}=A$. pintoi com Brachiaria brizanta e Pueraria phaseoloides; $\mathrm{Ap}$ x $\mathrm{Bh}=A$. pintoi com B. humidicola, Pueraria phaseoloides e Calopogonium mucunoides; Ap x Café $=A$. pinto $i$ com cafeeiro.

Foram escolhidas sete áreas para a amostragem do solo, com diferentes espécies vegetais, correspondendo às seguintes coberturas: A. pintoi em monocultivo (ApMono); A. pintoi consorciado com Panicum maximum (Ap x Pm); A. pintoi consorciado com Brachiaria brizanta e Pueraria phaseoloides (Ap x Bb); A. pintoi consorciado com B. humidicola, $P$. phaseoloides e Calopogonium mucunoides (Ap x Bh); A. pintoi consorciado com cafeeiro (Ap x café); capoeira e mata. Estas três últimas áreas foram usadas como testemunhas. Excetuando as áreas de capoeira e mata, as demais fazem parte de áreas experimentais com tamanhos variando entre 1.800 e $3.400 \mathrm{~m}^{2}$. Em cada área foram coletadas quatro amostras simples de solo, na profundidade de $0-10 \mathrm{~cm}$, totalizando 28 amostras, correspondentes à estação seca (junho de 2004) e chuvosa (janeiro de 2005). Nos consórcios, os pontos de coleta foram localizados nas áreas onde o solo estava coberto com A. pintoi, e nas áreas de capoeira e mata, em pontos definidos aleatoriamente entre a vegetaçáo do sub-bosque.

Nas áreas com a presença do $A$. pintoi foram coletadas também amostras de estolóes com raízes, que foram utilizadas para avaliar os índices de colonização radicular por FMAs e também para estabelecer culturas armadilhas, com o objetivo de recuperar as espécies fúngicas que estavam colonizando a leguminosa forrageira. $\mathrm{O}$ ensaio foi conduzido em casade-vegetação da Embrapa Agrobiologia em Seropédica, RJ, durante oito meses, quando, então, foram extraídos e identificados os esporos dos FMAs.

Os segmentos de estolóes com raízes foram separados do solo, lavados cuidadosamente e plantados em vasos de $500 \mathrm{~mL}$. O substrato foi um Planossolo de textura arenosa, coletado no Campo Experimental do Terraço, na Embrapa Agrobiologia, que apresentou as seguintes características

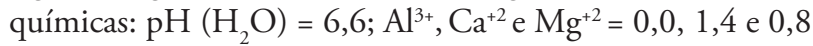
cmol $\cdot \mathrm{dm}^{-3}$, respectivamente; $\mathrm{P}$ e $\mathrm{K}=9,0$ e $69,0 \mathrm{mg} \cdot \mathrm{dm}^{-3}$, respectivamente; Matéria orgânica, C e N $=11,4,6,6$ e 0,88 $\mathrm{g} . \mathrm{kg}^{-1}$, respectivamente. $\mathrm{O}$ substrato foi esterilizado, por duas autoclavagens em dias consecutivos, a $120^{\circ} \mathrm{C}$ por $60 \mathrm{~min}$. Junto com os segmentos de estolóes foi semeado Brachiaria decumbens como planta isca, por sua característica de servir como planta hospedeira para muitas espécies de FMAs (Howeler et al., 1987; Simpson \& Daft, 1990; Colozzi-Filho $\&$ Balota, 1994a), facilitando, assim, a recuperação dos fungos associados às raízes do amendoim forrageiro.

$\mathrm{Na}$ semeadura foram colocadas cinco sementes por vaso e trinta dias após a emergência, as plântulas foram desbastadas, cortando-as rente à superfície do substrato, deixando uma planta por vaso. A irrigação foi feita regularmente com água deionizada, duas vezes ao dia, quando necessário, de modo a evitar o excesso de água e/ou ressecamento do substrato. Após oito meses do início do experimento, suspendeu-se a irrigação até o secamento das plantas. A parte aérea foi descartada, o solo (substrato) foi homogeneizado e tomado uma amostra de cada vaso. A extraçáo e contagem dos esporos foram feitas da forma descrita a seguir.

A densidade de esporos em $50 \mathrm{~cm}^{3}$ de solo foi determinada por contagem em placa canelada, conforme os procedimentos de extração por peneiramento úmido e centrifugação diferencial (Gerdemann \& Nicolson, 1963; Jenkins, 1964), usando peneiras de 1000, 250 e 0,53 $\mu \mathrm{m}$. Após a contagem, os esporos foram transferidos para uma placa de Petri, separandose, aleatoriamente, uma quarta parte do total dos esporos. Estes foram agrupados pelas características de tamanho, cor e forma, e os grupos foram colocados em lâminas para microscopia com álcool polivinil em lactoglicerol (PVLG). Na mesma lâmina, um segundo grupo de esporos foi montado com PVLG + reagente de Melzer (1:1), sob outra lamínula e quebrados cuidadosamente para a exposição das paredes internas. Os resultados da reação de cor ao reagente de Melzer foram utilizados para caracterizar taxonomicamente as paredes dos esporos, melhorando, em alguns casos, a visibilidade, especialmente daqueles esporos com paredes aderentes ou muitos finas.

A identificação das espécies dos FMAs foi feita segundo Schenck \& Perez (1988), com as descriçôes morfológicas disponíveis na página da International Culture Collection of Arbuscular Mycorrhizal Fungi - INVAM (http://invam. caf.wvu.edu). Os caracteres taxonômicos incluíram número e tipo de camadas das paredes dos esporos e sua reação ao reagente de Melzer, características das paredes internas, quando presentes, morfologia da hifa de sustentação no ponto de fixação do esporo e variação da cor e tamanho dos esporos. Para determinar a taxa de colonização radicular, as raízes foram clareadas e coloridas de acordo com Koske \& Gemma (1989) e Grace \& Stribley (1991). A avaliação da colonização foi feita com auxilio de microscópio estereoscópico, pelo método da interseção em placa quadriculada (Giovannetti \& Mosse, 1980).

Foram estimados, para cada área, índices de diversidade, calculados como indicado na Tabela 2. Para os cálculos, o número de esporos foi considerado como uma estimativa do número de indivíduos em cada amostra. Os dados obtidos para densidade de esporos foram transformados para log x e submetidos à análise de variância, usando o pacote estatístico Sisvar 4.6 para Windows. Os dados de abundância relativa das espécies de FMAs foram submetidos à análise multivariada de agrupamento, utilizando como medida de similaridade/ dissimilaridade a distância Euclidiana, e como método de 
Tabela 2 - Índices usados para descrever as comunidades de FMAs.

\begin{tabular}{|c|c|}
\hline Densidade de esporos (DE) & $\mathrm{DE}=$ Número de esporos em $50 \mathrm{~cm}^{3}$ de solo \\
\hline Riqueza de espécies (RE) & $\mathrm{RE}=$ Número de espécies de FMAs identificadas na amostra de solo \\
\hline \multirow{2}{*}{ Abundância relativa (AR) } & \multirow{2}{*}{$\mathrm{AR}=\frac{\text { número de esporos de uma espécie }}{\mathrm{n}^{\circ} \text { total de esporos identificados na amostra }} \times 100$} \\
\hline & \\
\hline Freqüência Relativa (FR) & $\mathrm{FR}=\frac{\mathrm{n}^{\circ} \text { de amostras onde uma espécie ocorre }}{\text { número total de amostras de solo }} \times 100$ \\
\hline Índice de diversidade Shannon-Wiener (H') & $\mathrm{H}^{\prime}=-\Sigma \mathrm{Pi} \ln \mathrm{Pi}$ \\
\hline Equitabilidade de Pielou (J') & $J^{\prime}=H^{\prime} / H^{\prime} \max$ \\
\hline Índice de dominância de Simpson (D) & $\mathrm{D}=\Sigma[\mathrm{ni}(\mathrm{ni}-1) / \mathrm{N}(\mathrm{N}-1)]$ \\
\hline
\end{tabular}

Pi: é a abundância relativa de cada espécie identificada por amostra, calculada pela fórmula: $\mathrm{Pi}=\mathrm{ni} / \mathrm{N}$;

ni: é o $\mathrm{n}^{0}$ de esporos de uma espécie:

$\mathrm{N}$ : é o número total de esporos identificados na amostra;

H': é calculado pela formula In S;

H'max é o máximo H':

S: é o número total de espécies identificadas por amostra.

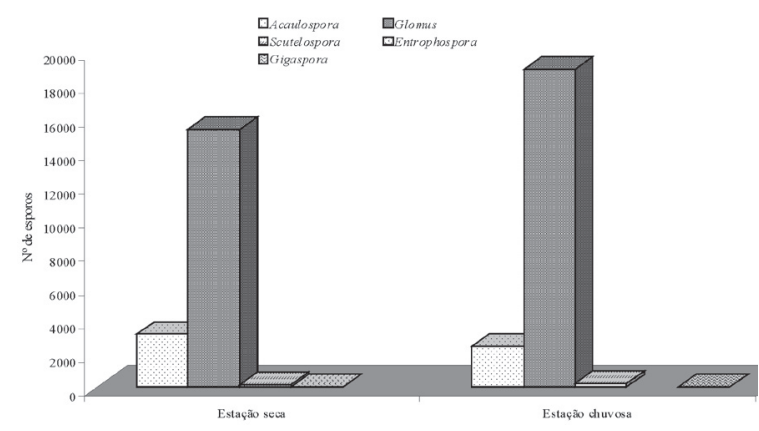

Figura 1 - Número total de esporos, por gênero de FMAs, nas duas estações de coleta estudadas.

ligação o de Ward (1963). Esta análise foi feita com auxílio do programa STATISTICA 5.0 para Windows.

\section{RESULTADOS E DISCUSSÃO}

Foram extraídos das áreas amostradas um total de 18.594 esporos de FMAs na estação seca e 21.470 na estação chuvosa. Desse total, foram identificadas 21 espécies pertencentes a cinco gêneros: Glomus (9), Acaulospora (7), Scutellospora (3), Entrophospora e Gigaspora (1). Os gêneros Glomus, Acaulospora e Scutellospora ocorreram nas duas estaçóes, enquanto que Entrophospora apenas na seca. Por outro lado, Gigaspora ocorreu somente na estação chuvosa. Glomus foi o gênero predominante nas duas estaçóes de coleta (Figura1).

A análise por cobertura vegetal também mostrou o domínio do gênero Glomus em ambas as estaçōes de coleta, excetuando-se as áreas de capoeira e mata onde houve prevalência do gênero Acaulospora no período seco e Glomus no chuvoso (Tabela 3). A presença de espécies de gramíneas nas áreas Ap x Pm, Ap x Bb e Ap x Bh parece favorecer as espécies de Glomus, onde se verificou a maior ocorrência e abundância deste gênero. De uma maneira geral, as espécies de Glomus foram mais abundantes nas áreas de pastagem de gramíneas com leguminosas herbáceas, enquanto que nas

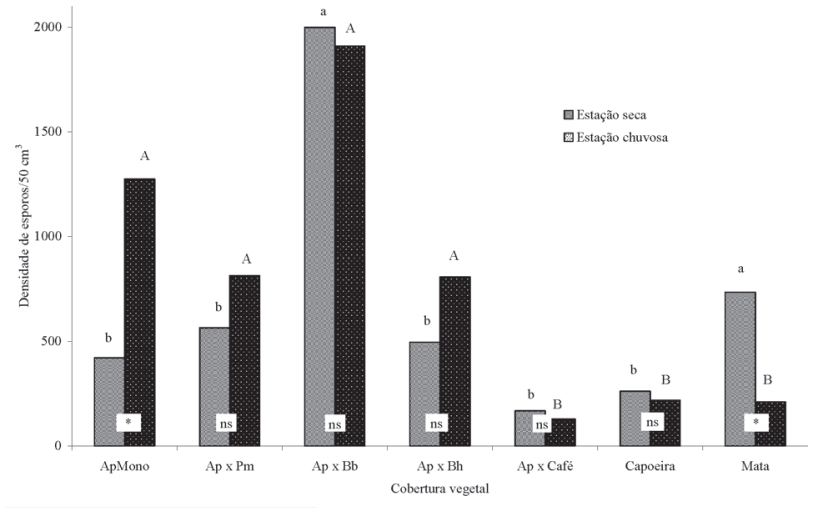

Figura 2 - Densidade de esporos de FMAs nas duas estações de coleta, em sete áreas. $A p M o n o=A$. pintoi em monocultivo; $\mathrm{Ap} \times \mathrm{Pm}=A$. pintoi consorciado com Panicum maximum; $\mathrm{Ap} \times \mathrm{Bb}=A$. pintoi consorciado com Brachiaria brizanta e Pueraria phaseoloides; $\mathrm{Ap} \times \mathrm{Bh}=A$. pintoi consorciado com B. humidicola, P. phaseoloides e Calopogonium mucunoides; Ap x Café $=A$. pintoi consorciado com cafeeiro; letras iguais em uma mesma estação representam a não existência de diferenças significativas pelo teste de ScottKnott $(p>0,05) ;{ }^{*}$ e ns indicam diferenças significativas ou não entre as estações pelo teste $\mathrm{F}$ ao nível de $5 \%$ de probabilidade (dados transformados: raiz de $x+1)$.

áreas com árvores e arbustos (cafeeiro, capoeira e mata) houve predomínio de espécies de Acaulospora, principalmente na estação seca.

$\mathrm{Na}$ maioria das áreas amostradas, a dominância da espécie $G$. macrocarpum pode estar associada à presença de gramíneas, sugerindo uma alta afinidade fungo-planta entre estes simbiontes, nas condiçôes edafoclimáticas locais. Esta afinidade parece estender-se, também, ao amendoim, já que no monocultivo dessa forrageira, verificou-se uma abundância relativa de $G$. macrocarpum superior a $70 \%$, nas duas estaçóes (Tabela 3). Estes resultados também corroboram a grande plasticidade de G. macrocarpum em adaptar-se a áreas com diferentes graus de perturbação e a diferentes plantas hospedeiras, visto que na área de mata sua abundância relativa foi de $27 \%$ na estação seca e $65 \%$ na chuvosa. 


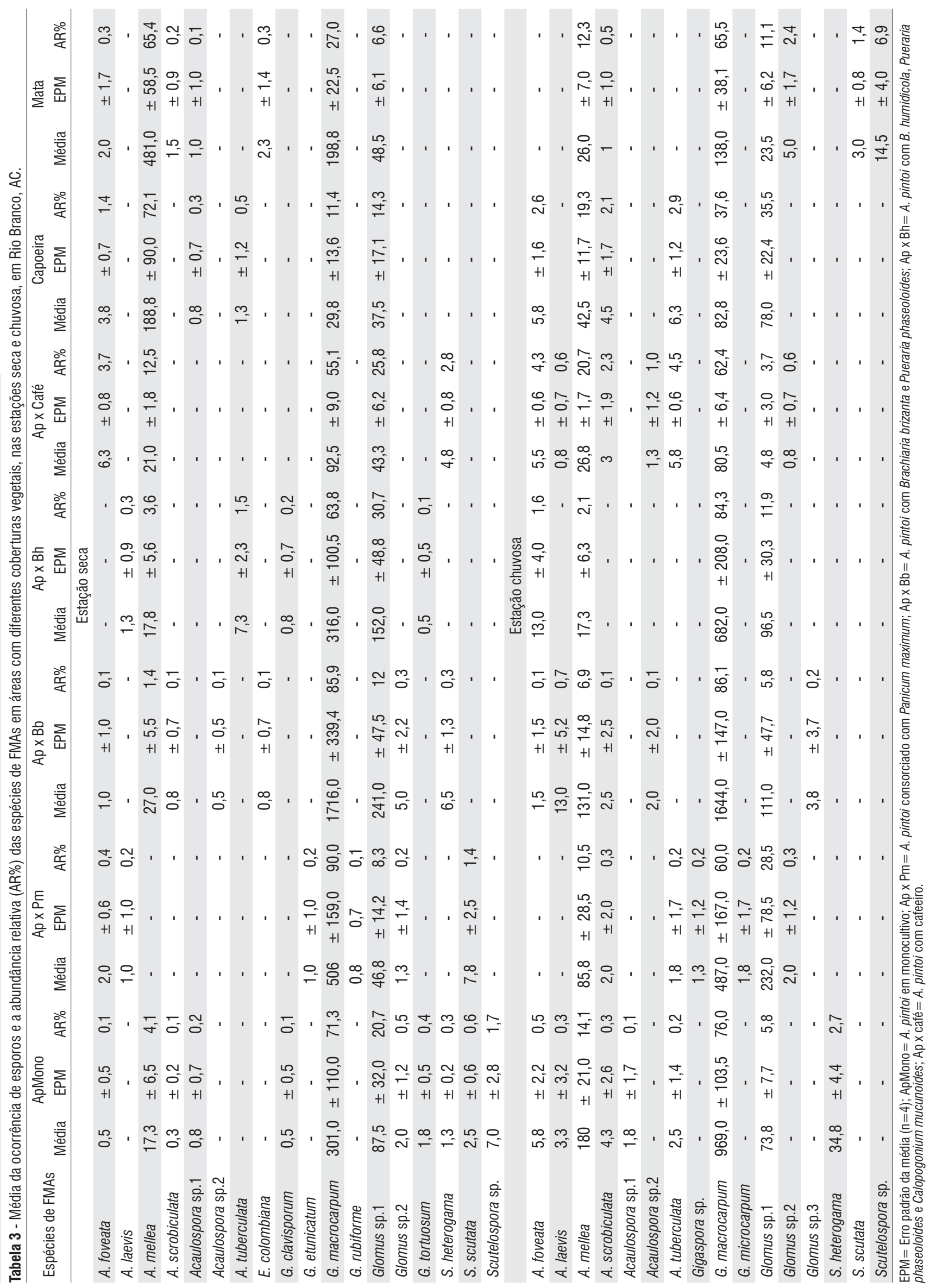


Silva Júnior (2004), estudando as comunidades de FMAs associadas à pupunha e ao cupuaçu, em sistema agroflorestal e em monocultivo na Amazônia Central, e Bennedeti et al. (2005), avaliando a diversidade de FMAs na cultura do milho, após uso de espécies leguminosas de cobertura de solo em Santa Maria, RS reportaram os gêneros Acaulospora e Glomus como os mais freqüentes. Resultados similares foram documentados por Silva et al. (2006), em estudo realizado em áreas cultivadas, sob pousio e de floresta secundária na Serra do Mar em São Paulo. De acordo com Carrenho (1998), estes gêneros apresentam maior capacidade de adaptação a solos submetidos a diferentes cultivos, com variações nos teores de matéria orgânica, calagem, textura, entre outros fatores,

\section{(A)}

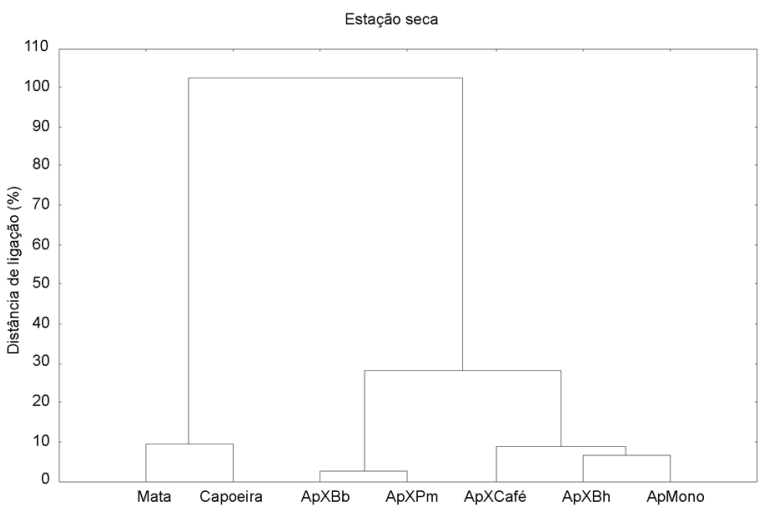

(B)

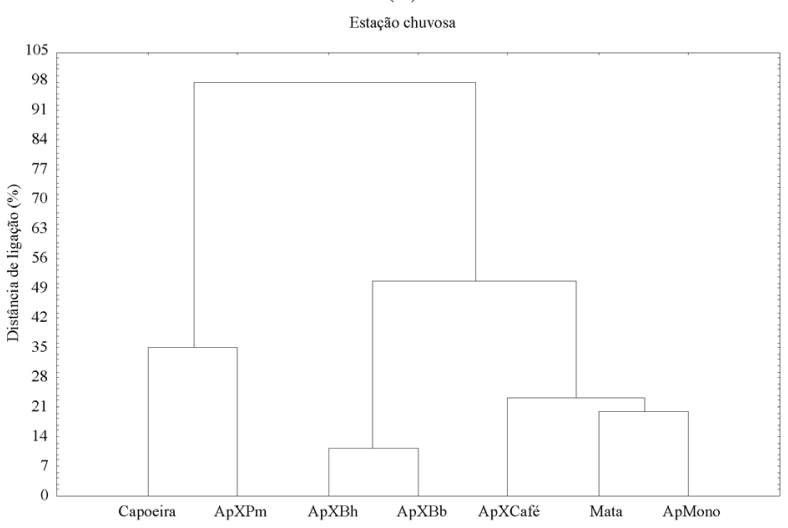

Figura 4 - (em arquivo anexo). Análise de agrupamento (distância euclidiana, método de Ward) baseado na abundância relativa das espécies de FMAs em cada sítio nas estações seca $(A)$ e chuvosa (B). ApMono $=A$. pintoi em monocultivo; $\mathrm{Ap} \times \mathrm{Pm}=A$. pintoi consorciado com Panicum maximum; $\mathrm{Ap} \mathrm{x}$ $\mathrm{Bb}=A$. pintoi consorciado com Brachiaria brizanta e Pueraria phaseoloides; $\mathrm{Apx}$ $\mathrm{Bh}=A$. pintoi consorciado com $B$. humidicola, $P$. phaseoloides e Calopogonium mucunoides; Ap x Café=A. pintoi consorciado com cafeeiro.

demonstrando que as espécies pertencentes a estes gêneros são resistentes a alteraçóes ambientais e que estão adaptadas a diferentes regióes.

Quando se compara a densidade de esporos (DE) nas sete áreas de estudo, verifica-se que o consórcio $A$. pintoi x $B$. brizanta x P. phaseoloides (Ap x Bb) apresentou as maiores densidades, independente da estação avaliada (Figura 2). Na estação seca, a DE na área Ap x Bb não diferiu significativamente da obtida na mata, sendo ambas significativamente superiores às demais coberturas vegetais. $\mathrm{Na}$ estação chuvosa houve a formação de dois grupos distintos, sendo o primeiro constituído pelas áreas de amendoim em monocultivo e consorciado com gramíneas, as quais não diferiram entre si, sendo, porém, superiores ao segundo grupo formado pelas testemunhas, que também não diferiram entre si. Apenas nas áreas ApMono e mata ocorreram efeito significativo da estação de coleta sobre a DE.

$\mathrm{Na}$ área ApMono, a DE foi significativamente maior na estaçáo chuvosa, enquanto que na área de mata, o maior valor foi registrado na estação seca. Esse resultado devese, possivelmente, às diferenças na estrutura da vegetação, aos picos vegetativos, reprodutivos e fotossintéticos das comunidades de plantas, bem como as diferentes estratégias de sobrevivência dos FMAs nestes ecossistemas.

De maneira geral, na área ApMono e nas áreas em que estão presentes espécies de gramíneas (Ap x Pm, Ap x Bb e Ap x Bh), ocorreu maior densidade de esporos. Nestas áreas, também se observa um maior equilíbrio na DE entre as estaçóes de coleta, provavelmente refletindo uma menor variabilidade fisiológica das plantas destes agrossistemas entre as duas estaçôes. A maior eficiência fotossintética (característica das plantas C4) proporciona vantagens ecológicas às gramíneas, dando a elas a oportunidade de crescer mais rápido, praticamente o ano todo (Ludlow \& Wilson, 1970; Fisher \& Thornton, 1989), favorecendo as relaçôes simbióticas com microrganismos, proporcionando aos FMAs associados, fotoassimilados em abundância e permitindo a dominância dos FMAs mais compatíveis na associação com as gramíneas.

As maiores taxas de colonização foram registradas na área $\mathrm{Ap} \times \mathrm{Bh}$, em ambas as épocas de estudo. Nas áreas Ap x Bb e Ap $\times$ Bh, onde o amendoim foi consorciado com braquiárias, observaram-se os maiores níveis de colonização micorrízica, sugerindo que estas gramíneas favorecem a colonização do amendoim. O monocultivo do amendoim apresentou taxas de colonização superior à área Ap x Pm, e semelhante à área de consórcio com cafeeiro, nas duas estaçóes avaliadas (Figura 3).

As gramíneas, principalmente as braquiárias, são plantas eficientes na multiplicação de FMAs, favorecendo, conseqüentemente, a colonização do amendoim. Caso o fungo seja eficiente e a fertilidade do solo baixa, tanto as gramíneas como as leguminosas podem se beneficiar da simbiose melhorando, portanto, sua nutrição e produção. Isso pode explicar, em parte, a elevada adaptabilidade destas plantas aos solos ácidos e deficientes em P (Howeler et al., 1987).

No monocultivo de amendoim, alguns índices de diversidade são maiores ou comparáveis aos obtidos nas outras 


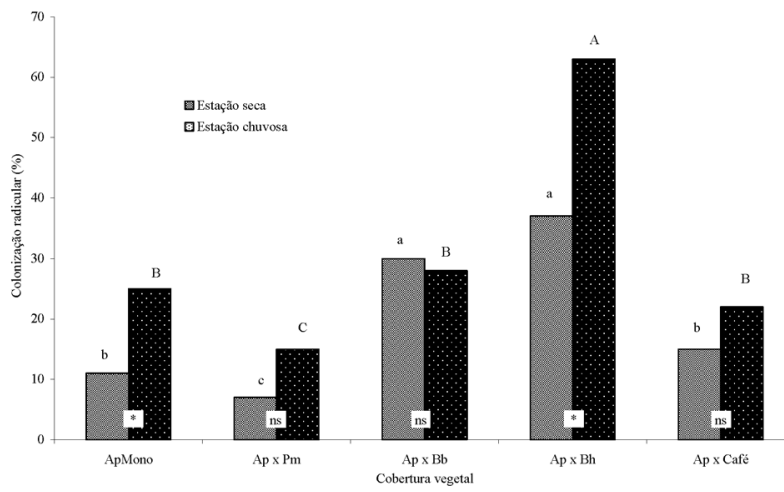

Figura 3 - Taxa de colonização radicular do A. pintoi, por FMAs, nas duas estações de coletas em cinco agrossistemas. ApMono=A. pinto $i$ em monocultivo; $\mathrm{Ap}$ x $\mathrm{Pm}=A$. pintoi consorciado com Panicum maximum; $\mathrm{Ap} \mathrm{x}$ $\mathrm{Bb}=$ A. pintoi consorciado com Brachiaria brizanta e Pueraria phaseoloides; Ap $\mathrm{xBh}=$. pintoi consorciado com Brachiaria humidicola, Pueraria phaseoloides e Calopogonium mucunoides; Ap x Café=A. pintoi consorciado com cafeeiro; letras iguais em uma mesma estação representam a não existência de diferenças significativas pelo teste de Scott-Knott $(p>0,05) ;{ }^{*}$ e ns indicam diferenças significativas ou não entre as estações pelo teste $\mathrm{F}$ ao nível de 5 $\%$ de probabilidade (dados transformados: raiz de $x+1$ ).

Tabela 4 -Densidade de esporos e diversidade de FMAs em áreas com diferentes tipos de vegetação, nas estações seca e chuvosa em Rio Branco, AC.

\begin{tabular}{|c|c|c|c|c|c|}
\hline \multirow{2}{*}{$\begin{array}{l}\text { Cobertura } \\
\text { vegetal }\end{array}$} & \multirow{2}{*}{$\begin{array}{c}D E \\
(n=4)\end{array}$} & \multirow{2}{*}{$\mathrm{RE}$} & \multicolumn{3}{|c|}{ Índices } \\
\hline & & & Shannon $\left(H^{\prime}\right)$ & Simpson (D) & Pielou (J') \\
\hline & \multicolumn{5}{|c|}{ Estação seca } \\
\hline ApMono & 422 & 12 & 0,388 & 0,553 & 0,359 \\
\hline Ap $\times \mathrm{Pm}$ & 565 & 8 & 0,186 & 0,810 & 0,206 \\
\hline $\mathrm{Ap} \times \mathrm{Bb}$ & 1999 & 9 & 0,213 & 0,752 & 0,223 \\
\hline $\mathrm{Ap} \times \mathrm{Bh}$ & 496 & 7 & 0,374 & 0,502 & 0,443 \\
\hline Ap x café & 168 & 5 & 0,504 & 0,385 & 0,721 \\
\hline Capoeira & 262 & 6 & 0,375 & 0,554 & 0,482 \\
\hline Mata & 735 & 7 & 0,376 & 0,506 & 0,445 \\
\hline Média $(\mathrm{n}=28)$ & 663,85 & 7,71 & - & - & - \\
\hline \multirow[t]{2}{*}{ Desvio padrão } & 617,99 & 2,29 & - & - & - \\
\hline & \multicolumn{5}{|c|}{ Estação chuvosa } \\
\hline ApMono & 1275 & 9 & 0,359 & 0,602 & 0,377 \\
\hline $\mathrm{Ap} \times \mathrm{Pm}$ & 814 & 8 & 0,420 & 0,451 & 0,465 \\
\hline $\mathrm{Ap} \times \mathrm{Bb}$ & 1909 & 8 & 0,237 & 0,750 & 0,262 \\
\hline $\mathrm{Ap} \times \mathrm{Bh}$ & 808 & 4 & 0,237 & 0,726 & 0,394 \\
\hline Ap x café & 129 & 9 & 0,524 & 0,438 & 0,550 \\
\hline Capoeira & 219 & 6 & 0,578 & 0,307 & 0,742 \\
\hline Mata & 211 & 7 & 0,494 & 0,455 & 0,584 \\
\hline Média ( $\mathrm{n}=28)$ & 766,43 & 7,29 & - & - & - \\
\hline Desvio padrão & 656,07 & 1,80 & - & - & - \\
\hline
\end{tabular}

ApMono $=A$. pintoi em monocultivo; $A$ pxPm $=A$. pintoi consorciado com Panicum maximum; $\mathrm{Ap} \times \mathrm{Bb}=$ A . pintoi com Brachiaria brizanta e Pueraria phaseoloides; Ap $\mathrm{x}$ $\mathrm{Bh}=A$. pintoi com $B$. humidicola, Pueraria phaseoloides e Calopogonium mucunoides; Ap x Café=A. pintoi com cafeeiro. $\mathrm{DE}=$ Densidade de esporos; $\mathrm{RE}=$ Riqueza de espécies. coberturas vegetais, como foram os casos da riqueza de espécies (RE) e da densidade de esporos (DE), principalmente na estação chuvosa. Considerando-se o índice de Shannon (H'), a diversidade de FMAs na área ApMono ( $\left.\mathrm{H}^{\prime}=0,388\right)$ foi maior do que a verificada nos consórcios com gramíneas com exceção da área Ap x Pm, na estação chuvosa (Tabela 4).

De maneira geral, a maior dominância de espécies foi verificada nas áreas com gramíneas, com destaque para Ap x Pm, com índice de Simpson (D) de 0,810 na estação seca. Por sua vez, o ApMono exibiu o maior índice $(\mathrm{D}=0,602)$ na chuvosa. Quanto à equitabilidade foi observado que as áreas mais complexas, quanto à cobertura vegetal, tendem a serem mais eqüitativos em relação às pastagens consorciadas (Tabela 4). Estes resultados confirmam que as gramíneas favorecem o gênero Glomus, como anteriormente discutido.

$\mathrm{Na}$ transição de sistemas naturais, mais estáveis, para agrossistemas, geralmente ocorre um aumento na densidade de FMAs. Segundo Sieverding (1991), isso se deve ao aumento da esporulação das espécies em resposta à instabilidade e aos estresses ambientais. Com isto, há um aumento da dominância de algumas espécies mais adaptadas a estas condiçóes, conforme verificado no presente estudo. De maneira geral, se verifica que na área estudada a ordem da diversidade segue o seguinte padrão: maior diversidade $\left(\mathrm{H}^{\prime}\right)$, maior equitabilidade (J') e menor dominância (D) ocorreram nas áreas Apxcafé, capoeira e mata; o inverso, ou seja, menor diversidade (H'), menor equitabilidade (J') e maior dominância (D) ocorreram nas áreas ApxPm, ApxBb e ApxBh (pastagens de gramíneas consorciadas), ficando o monocultivo do amendoim forrageiro (ApMono) com índices intermediários (Tabela 3).

Estes resultados mostram que o amendoim forrageiro em monocultivo, mesmo sendo o agrossistema de aparente menor complexidade, favorece a ocorrência de diferentes espécies de FMAs, sugerindo que esta leguminosa é bastante promíscua, servindo como uma boa hospedeira para os fungos micorrízicos autóctones. Segundo Saggin-Júnior \& Siqueira (1996), as razóes pelas quais as leguminosas influenciam a ecologia dos FMAs ainda são desconhecidas. Possivelmente, a capacidade deste grupo de plantas de produzir uma grande variedade de metabólitos, como flavonóides, possa explicar a elevada aptidão hospedeira do amendoim forrageiro, favorecendo a colonização e a esporulaçáo dos FMAs associados (Baptista \& Siqueira, 1994; Romero \& Siqueira, 1996).

$\mathrm{Na}$ Tabela 5 são apresentadas a freqüência (FR) e abundância relativas (AR) das espécies de FMAs nas estaçóes seca e chuvosa. Glomus macrocarpum foi a espécie de maior freqüência e abundância nas duas estaçóes. A segunda espécie mais freqüente foi Acaulospora foveata, na estação seca, e Glomus sp. 1, na estaçáo chuvosa, ambas ocorrendo em $50 \%$ das amostras. Em abundância, destacaram-se, ainda, A. mellea e Glomus sp. 1, nas estaçóes seca e chuvosa, respectivamente 
Tabela 5 - Freqüência e Abundância Relativas de espécies de FMAs em sete áreas com diferentes tipos de cobertura vegetal, nas estações seca e chuvosa em Rio Branco, AC.

\begin{tabular}{|c|c|c|c|c|}
\hline \multirow{2}{*}{ Espécies de FMAs } & \multicolumn{2}{|c|}{ Freqüência (\%) } & \multicolumn{2}{|c|}{ Abundância (\%) } \\
\hline & Est. seca & Est. chuvosa & Est. seca & Est. chuvosa \\
\hline Acaulospora foveata & 50,0 & 32,1 & 0,33 & 0,54 \\
\hline A. laevis & 10,7 & 17,9 & 0,05 & 0,29 \\
\hline A. mellea & 17,9 & 14,3 & 16,19 & 8,66 \\
\hline A. scrobiculata & 14,3 & 32,1 & 0,05 & 0,29 \\
\hline $\begin{array}{l}\text { Acaulospora sp.1 (esporo } \\
\text { amarelo) }\end{array}$ & 14,3 & 3,6 & 0,05 & 0,03 \\
\hline $\begin{array}{l}\text { Acaulospora sp.2 (esporo } \\
\text { hialino) }\end{array}$ & 3,6 & 7,1 & 0,01 & 0,06 \\
\hline A. tuberculata & 3,6 & 7,1 & 0,18 & 0,28 \\
\hline $\begin{array}{l}\text { Entrophospora } \\
\text { colombiana }\end{array}$ & 10,7 & - & 0,06 & - \\
\hline Gigaspora sp. & - & 3,6 & - & 0,02 \\
\hline $\begin{array}{l}\text { Glomus clavisporum } \\
\text { (Sclerocystis) }\end{array}$ & 3,6 & - & 0,03 & - \\
\hline G. etunicatum & 3,6 & - & 0,02 & - \\
\hline G. macrocarpum & 96,4 & 89,3 & 68,01 & 69,48 \\
\hline G. microcarpum & - & 3,6 & - & 0,03 \\
\hline $\begin{array}{l}\text { G. rubiforme } \\
\text { (Sclerocystis) }\end{array}$ & 3,6 & - & 0,02 & - \\
\hline $\begin{array}{l}\text { Glomus sp.1 (esporo } \\
\text { branco) }\end{array}$ & 3,6 & 50,0 & 14,12 & 10,55 \\
\hline $\begin{array}{l}\text { Glomus sp.2 (esporo } \\
\text { castanho) }\end{array}$ & 21,4 & 10,7 & 0,18 & 8,84 \\
\hline $\begin{array}{l}\text { Glomus sp. } 3 \text { (esporo } \\
\text { hialino) }\end{array}$ & - & 3,6 & - & 0,06 \\
\hline G. tortuosum & 3,6 & - & 0,05 & - \\
\hline $\begin{array}{l}\text { Scutelospora } \\
\text { heterogama }\end{array}$ & 3,6 & 3,6 & 0,27 & 0,59 \\
\hline S. scutata & 7,1 & 3,6 & 0,22 & 0,05 \\
\hline $\begin{array}{l}\text { Scutelospora sp. (esporo } \\
\text { castanho) }\end{array}$ & 3,6 & 7,1 & 0,15 & 0,25 \\
\hline
\end{tabular}

(Tabela 5). Resultados similares foram reportados por Silva Júnior (2004) e Silva et al. (2006), em diferentes ecossistemas e sistemas de cultivo, mostrando o amplo grau de distribuição destas espécies fúngicas na zona tropical.

Com os dados de abundância relativa das espécies de FMAs foram construídos os dendrogramas de agrupamento para as áreas estudadas (Figura 4). Na estação seca (Figura 4A), de maneira geral, as áreas foram agrupadas de acordo com a complexidade da cobertura vegetal.

As áreas de mata e capoeira formaram um grupo com cerca de $90 \%$ de similaridade, porém, não mostrando nenhuma similaridade com os grupos formados por áreas cultivadas. Os outros dois grupos exibiram similaridade de $70 \%$. Um deles agrupa o consórcio $A$. pintoi $\mathrm{x} B$. brizantha $\mathrm{x}$ P. phaseoloides $\mathrm{e}$ A. pintoi $\mathrm{x} P$. maximum com similaridade de $97 \%$. O outro grupo, com $90 \%$ de similaridade foi formado pelo $A$. pintoi x cafeeiro, $A$. pintoi $\times$ B. humidicola $\times$ P. phaseoloides $\times$ $C$. mucunoides e pelo $A$. pintoi em monocultivo, estando os dois últimos agrossistemas formando um subgrupo com $92 \%$ de similaridade.

$\mathrm{Na}$ estação chuvosa (Figura 4B), a formação dos grupos parece seguir padróes mais aleatórios, não sendo possível perceber tendências associadas à vegetação, com exceção do agrupamento dos dois agrossistemas com a presença de espécies do gênero Brachiaria (ApxBh e $\mathrm{ApxBb}$ ) com similaridade aproximada de $90 \%$.

Os resultados dos agrupamentos mostram que o grau de similaridade entre os sítios varia com a estação. Esta variaçáo, provavelmente, se deve aos fatores que afetam a colonizaçáo micorrízica, como as variaçôes climáticas, que modificam as relaçóes hídricas nas áreas de acordo com a estação. Outros fatores importantes são os relacionados à planta hospedeira em suas diferentes fases fenológicas, e aos próprios FMAs, que podem apresentar diferentes estratégias de sobrevivência em cada estação, ou seja, na estação seca, quando os recursos do meio são mais escassos, os agrossistemas foram agrupados seguindo a complexidade da vegetaçáo, sendo mais similares os agrossistemas mais complexos, como a mata e a capoeira. Já na estação chuvosa, quando há uma maior disponibilidade de recursos e as plantas encontram-se em picos vegetativos ou reprodutivos, os agrupamentos pareceram seguir padrôes mais aleatórios em relação à complexidade da cobertura vegetal. Isto possivelmente se deve à capacidade do $A$. pintoi de ser um bom hospedeiro para diferentes espécies de FMAs, tornando os agrossistemas mais eqüitativos, justificando o grupo formado pela mata e o monocultivo do $A$. pintoi, com cerca de $80 \%$ de similaridade (Figura 4B).

Nos vasos de cultura armadilhas, foram recuperadas as espécies Acaulospora. foveata, A. scrobiculata, A. tuberculata, Acaulospora sp. 1, Acaulospora sp. 2, Gigaspora sp., Glomus sp. 1, Glomus sp. 2 e Glomus sp. 3, sugerindo uma grande diversidade de fungos colonizando as raízes de $A$. pintoi. Algumas espécies extraídas do solo não foram recuperadas na cultura armadilha, entre elas a espécie dominante Glomus macrocarpum, possivelmente devido às condiçóes edafoclimáticas do cultivo ter sido diferentes das áreas originais, indicando diferenças de adaptação ao ambiente. A falta de adaptação ao ambiente de cultivo da cultura armadilha também foi relatado por Carneiro et al. (1999), estudando o efeito da inoculação de uma mistura de Glomus etunicatum, G. clarum, Gigaspora margarita e Acaulospora scrobiculata, no estabelecimento de Stylosanthes guianensis, Melinis minutiflora e Brachiaria decumbens em Latossolo Vermelho-Escuro, na regiáo de Lavras, MG. No período de estudo, foi verificado que, dos fungos introduzidos, foram recuperados apenas as espécies G. etunicatum e A. scrobiculata.

Os resultados deste trabalho sugerem que o Arachis pintoi contribui para aumentar a presença de FMAs nos 
agrossistemas. A associação com grande número de espécies de FMAs pode, em parte, explicar o bom desempenho dessa leguminosa em diversas condições de cultivo. Resultados semelhantes foram reportados por Bennedeti et al. (2005), avaliando a diversidade de FMAs na cultura do milho após uso de algumas leguminosas como cobertura do solo. ColozziFilho \& Balota (1994b) citam estudos feitos em condiçôes de campo, que demonstram que o cultivo das leguminosas Leucaena leucocephala, Crotalaria spectabilis, C. breviflora, C. mucronata, Mucuna aterrima, M. pruriens e Vigna unguiculata favorecem a esporulação, a abundância e a diversidade de espécies de FMAs no solo.

Estas informaçóes podem ser úteis no desenvolvimento de sistemas baseados no manejo dos FMAs autóctones, visando aumentar a sustentabilidade e o rendimento das práticas agrícolas nas regióes tropicais. A ampla associação com fungos micorrízicos, além de outras características benéficas do amendoim forrageiro, como a fixaçáo biológica de nitrogênio, o qualificam como uma boa opçáo de uso como componente de sistemas baseados no manejo ecológico do solo.

\section{CONCLUSÕES}

O amendoim forrageiro foi colonizado por FMAs autóctones, hospedando pelo menos cinco gêneros, sendo Glomus, Acaulospora e Scutelospora os mais representativos. G. macrocarpum foi a espécie dominante na rizosfera desta forrageira;

As áreas com gramíneas apresentam menor diversidade, menor equitabilidade e maior dominância de espécies de FMAs;

A diversidade das espécies de FMAs foi proporcional à complexidade dos agrossistemas, sendo maior na estação chuvosa;

$\mathrm{O}$ amendoim forrageiro em monocultivo apresenta índices de diversidade de FMAs comparáveis aos dos agrossistemas mais complexos, mostrando que pode aumentar a presença destes fungos nos sistemas produtivos e melhorar a qualidade biológica do solo.

\section{BIBLIOGRAFIA CITADA}

Acre. Governo do Estado. Programa Estadual de Zoneamento Ecológico e Econômico do Acre: recursos naturais e meio ambiente. Rio Branco, 2000b. v.1. 116p.

Baptista, M.J.; Siqueira, J.O. 1994. Efeito de flavonóides na germinação e no crescimento assimbiótico de fungos micorrízicos vesículo-arbusculares. Revista Brasileira de Fisiologia, 6: 127134.

Bennedeti, T.; Antoniolli, Z.I.; Giracca, E.M.N.; Steffen, R.B. 2005. Diversidade de fungos micorrízicos arbusculares na cultura do milho após uso de espécies de plantas de cobertura de solo. Revista de Ciências Agroveterinárias, 4: 44-51.
Boddey, R.M.; Resende, C.P.; Pereira, J.M.; Cantarutti, R.B.; Alves, B.J.R.; Ferreira, E.; Richter, M.; Cadisch, G.; Urquiaga, S. 1995. Nitrogen cycle in pure grass and grass / legume pasturesevaluation of pasture sustainability, p. 307-319. In: IAEA/ FAO. Nuclear Techiniques in Soil-Plant Studies for Sustainable Agriculture and Environmental Preservation. Vienna, Austria.

Cadish, G.; Schunke, R.M.; Giller, K.E. 1994. Nitrogen cycling in a pure grass pasture and a grass-legume misture on a red latosol in Brazil. Tropical Grasslands, 28 :43-52.

Cantarutti, R.B. 1996. Dinâmica de nitrogênio em pastagens de Brachiaria humidicola em monocultivo e consorciada com Desmodium ovalifolium Cv. Itabela no sul da Bahia. Tese de Doutorado, Universidade Federal de Viçosa, Viçosa, Minas Gerais. 83pp.

Carneiro, M.A.C.; Siqueira, J.O.; Curi, N.; Moreira F.M.S. 1999. Efeitos da inoculação de fungos micorrízicos arbusculares e da aplicação de fósforo no estabelecimento de forrageiras em solo degradado. Pesquisa Agropecuária Brasileira, 34: 1669-1677.

Carrenho, R. 1998. Influência de diferentes espécies de plantas hospedeiras e fatores edáficos no desenvolvimento de fungos micorrizicos arbusculares (FMA). Tese de Doutorado, Universidade Estadual de São Paulo, Rio Claro, São Paulo. 227pp.

Colozzi-Filho, A.; Balota, E.L. 1994a. Micorrizas arbusculares, p. 383-418. In: Hungria, M.; Araújo, R.S (Ed). Manual de métodos empregados em estudos de microbiologia agrícola. Embrapa-SPI, Brasília, Distrito Federal.

Colozzi-Filho, A.; Balota, E.L. 1994b. Potencial de inóculo de fungos micorrízicos arbusculares em solo cultivado com cafeeiro e leguminosas de verão, 17/pp. In: Reunião Brasileira Sobre Micorrizas. 5. Resumos. Florianópolis, Santa Catarina.

Dandan, Z.; Zhiwei, Z. 2007. Biodiversity of arbuscular mycorrhizal fungi in the hot-dry valley of the Jinsha River, southwest China. Applied Soil Ecology, 37: 118-128.

Fisher, M.J.; Thornton, P.K. 1989. Growth and competition as factors in the persistence of legumes in pastures, p. 293-308. In: Marten, G.C.; Matches, A.G.; Barnes, R.F. et al. (Eds.) Persistence of Forage Legumes. ASA/CSSA/SSSA, Madison.

Gerdemann, J.W.; Nicolson, T.H. 1963. Spores of mycorrhizal endogone species extracted from Transaction of the Bristish Mycological Society, soil by wit sieving and decanting. Transactions of the British Mycological Society,. 46: 235-244.

Giovannetti, M.; Mosse, B. 1980. An evaluation of techniques to measure vesicular-arbuscular mycorrhizal infection in roots. New Phytologist, 84: 484-500.

Grace, C.; Stribley, D.P. 1991. A safer procedure for roution staining of vesicular-arbuscular mycorrhizal fungi. Mycological Research, 95: 1160-1162.

Howeler, R.H.; Sieverding, E.; SAIF, S.R. 1987. Practical aspects of mycorrhizal technology in some tropical crops and pastures. Plant and Soil, 100: 249-283.

Jenkins, W.R. 1964. A rapid centrifugal-floration technique for separating nematodes from soil. Plant Dis. Rep. 48:692. 
Koske, R.E.; Gemma, J.N. 1989. A modified procedure for stining roots to detect VA mycorrhizas. Mycological Research, 92: 486488.

Ludlow, M.M.; Wilson, G.L. 1970. Studies of the productivity of tropical pasture plants. II. Growth, photosynthesis, and respiration of 20 species of grasses and legumes in a controlled environment. Australian Journal of Agricultural Research, 21: 183-194.

Mesquita, C.C. 1996. O clima do estado do Acre. Rio Branco, Secretaria de Ciência Tecnologia e Meio Ambiente. 57pp.

Mesquita, C.C. Paiva, R.A. Estudos básicos das precipitaçóes do Acre. Rio Branco, Governo do Estado, 1995. 147p.

Oliveira, L.A.; Guitton, T.L.; Moreira, F.W. 1999. Relações entre as colonizaçóes por fungos micorrízicos arbusculares e teores de nutrientes foliares em oito espécies florestais da Amazônia. Acta Amazonica, 29: 183-193.

Oliveira, A.N.; Oliveira, L.A.; Figueiredo, A.F. 2003. Colonização micorrízica e concentração de nutrientes em três cultivares de bananeiras em um Latossolo Amarelo da Amazônia Central. Acta Amazonica, 33: 345-352.

Romero, A.G. F.; Siqueira J.O. 1996. Atividade de flavonóides sobre esporos do fungo micorrízico Gigaspora gigantea in vitro. Pesquisa Agropecuária Brasileira, 37: 517-522.

Saggin-Júnior, O. J.; Siqueira, J.O. 1996. Micorrizas arbusculares em cafeeiro. In: Siqueira, J.O. (ed.) Avanços em fundamentos e aplicaçôes de micorrizas. Universidade Federal de Lavras, Lavras, Minas Gerais. p. 203-254.

Schenck, N.C; Pérez, Y. 1988. Manual of the identification of $V A$ mycorrhizal fungi. 2a ed. INVAN. University of Florida. Gainesville, Florida. 241pp.

Schunke, R.M. 1998. Qualidade, decomposição e liberação de nutrientes da liteira de quatro cultivares de Panicum maximum Jacq. Tese de Doutorado, Universidade Federal Rural do Rio de Janeiro, Seropédica, RJ. 111 pp.
Sieverding, E. 1991. Vesicular-arbuscular mycorrhiza management in tropical agrosystems. GTZ, Eschborn. 371pp.

Simpson, D.; Daft, M. J. 1990. Spore production and mycorrhizal development in various tropical crop host infected with Glomus clarum. Plant and Soil, 121:171-178.

Silva, C.F. Da; Pereira, M. G.; Silva, E.M.R. Da; Correia, M.E.F; Saggin Junior, O.J. 2006. Fungos Micorrízicos Arbusculares Em Áreas no Entorno do Parque Estadual da Serra do Mar em Ubatuba, SP. Caatinga, 19:1-10.

Silva Júnior, J.P. 2004. Comunidades de Fungos Micorrizicos Arbusculares Associadas à Pupunha e ao Cupuaçu em Sistema Agroflorestal e em Monocultivo na Amazônia Central. Tese de Doutorado, Escola Superior de Agricultura Luiz de Queiroz, Piracicaba, São Paulo. 95pp.

Smith, S.E.; Gianinazzi-Pearson, V.; Koide, R.; Cairney, J.W.G. 1994. Nutrient transport in mycorrhizas: structure, physiology and consequences for efficiency of the symbiosis. Plant and Soil, 159: 103-113.

Thomas, R.J. 1992. The role of the legume in the nitrogen cycle of productivite and sustainable pastures. Grass and Forage Science, 47: 133-142.

Ward, J.H. 1963. Hierarchical Grouping to Optimize an Objective Function. Journal of the American Statistical Association, 58: 236-244.

Recebido em: 08/05/2008

Aceito em: 13/10/2009 